\title{
A INTERATIVIDADE NO TELEJORNALISMO: LACUNAS E POSSIBILIDADES PARA PENSAR A TEMÁTICA NO BRASIL
}

\author{
INTERACTIVITY IN THE NEWS ON TV: GAPS AND POSSIBILITIES TO \\ THINK THE THEME IN BRAZIL \\ LA INTERACTIVIDAD DEL PERIODISMO EN LA TV: LACUNAS Y
POSIBILIDADES PARA PENSAR LA TEMÁTICA EN BRASIL
}

\section{Resumo}

Pesquisadores do jornalismo no Brasil utilizam a palavra interatividade para se referir a fenômenos e comportamentos distintos. Este trabalho pretende apresentar as visões sobre este tema quando a temática específica é o telejornalismo. Foram observados os estudos apresentados no GT Jornalismo da Compós e os textos publicados na revista E-Compós, da mesma entidade, entre 2004 e 2010. A análise revelou, além de uma pequena inserção do tema, uma falta de aprofundamento sobre as maneiras como a interatividade pode surgir e os efeitos que isso provocará. A interatividade não pode ser confundida somente como constitutiva das novas mídias, mas deve ser entendida de modo mais amplo, como defendem Vilches (2003), Jenkins (2008), Scolari (2008), Jensen (2008).

Palavras-chave: Interatividade. Pesquisadores. Brasil. Telejornalismo.

\begin{abstract}
After verify that Brazilian journalism researches use interactivity for many different phenomenon and social behavior distinct, this paper intend to present the views about these themes in the specific discussion about the TV news program. It was observed the studies published in the Group of Work Journalism in Compós and the texts in E-Compós, during 2004 and 2010. The analysis shows few insertions and a lack for turn the interactivity studies more deep. For this, interactivity don't could be only a synonymous for news media, but is provoking big challenges nowadays, like says Vilches (2003), Jenkins (2008), Scolari (2008), Jensen (2008).
\end{abstract}

Key words: Interactivity. Researches. Brazil. TV News. 


\section{Resumen}

Después de verificar que los pesquisadores brasileños hablam de la interactividad en fenómenos y comportamientos distintos, este artículo objetiva presentar las diferentes visiones sobre estas temáticas en la específica discussion sobre el periodismo en la TV. Fueran observados los artículos do Grupo de Trabajo Periodismo Compós e los textos de la ECompos, entre 2004 y 2010. El análisis mostró una pequeña inserción de la interactividad y poca profundidad sobre este tema. Por eso, la interactividad no puede ser sinónimo de nuevas mídias, pero debe ser comprendida de una manera más amplia, como proponem Vilches (2003), Jenkins (2008), Scolari (2008), Jensen (2008).

Palabras clave: Interactividad. Pesquisadores. Brasil. Periodismo en la TV.

Esta obra está licenciada sob uma Licença Creative Commons

\section{INTRODUÇÃO}

Em estudos de teóricos brasileiros da comunicação, há o consenso de que as possibilidades interativas na televisão podem ser exponencialmente ampliadas com a TV Digital. A despeito da polêmica envolvendo os padrões tecnológicos já adotados ou que ainda serão escolhidos para o desenvolvimento de aplicativos e para a adoção do canal de retorno dos telespectadores, os estudiosos praticamente não explicitam o que entendem por interatividade. Pelo menos em trabalhos sobre a televisão, jornalismo e telejornalismo, foco deste estudo, há mais divagações em torno do assunto, muitas das quais dispersas em meio a outros temas, do que propriamente uma preocupação em definir o que poderia ser compreendido como interatividade e o quê de novo ela acrescentaria ou modificaria.

Na tentativa de apresentar os pontos de vista dos pesquisadores, neste trabalho serão descritas e analisadas opiniões lançadas no encontro anual da Compós e nas revistas quadrimestrais da mesma entidade, a E-Compós, entre 2004 e 2010. A escolha partiu do pressuposto de que os dois acervos, por serem iniciativas da Associação Nacional dos Programas de Pós-Graduação em Comunicação, podem ser bastante representativos das pesquisas em andamento no país. Como no encontro anual existem quinze Grupos de Trabalho (GT), a fim de atender aos objetivos deste estudo, foi selecionado para avaliação o grupo de Jornalismo a partir do entendimento de que a maior parte dos estudos em 
telejornalismo se enquadraria mais facilmente a ele, pois a criação do GT Televisão foi aprovada somente em 2010, com os primeiros trabalhos apresentados em 2011.

No GT da Compós, apenas seis artigos possuíam uma abordagem que poderiam servir para essa observação, dois no ano de 2008 e somente um em 2004, 2005, 2006 e 2010. Na Ecompós, a quantidade é maior, pois foram publicadas 18 edições da revista eletrônica ao longo do período. No total, faz parte do corpus um trabalho de 2004; dois de 2006, sendo um de cada uma das duas edições; cinco de 2007, todos do dossiê televisão; um de 2008; e dois de 2009. Deve-se ressaltar que para a seleção foram lidos todos os resumos dos artigos e, dentro desta totalidade, houve a separação dos textos que abordavam diretamente o telejornalismo, a televisão e/ou o jornalismo interativo. Essas duas últimas temáticas foram selecionadas porque elas poderiam trazer posicionamentos extensivos ao telejornalismo.

As citações dos trabalhos utilizadas por aqui servem para ilustrar aspectos ressaltados pelo(s) autor(es) e, mais ainda, auxiliarão nas reflexões deste estudo. Dessa forma, as considerações dos pesquisadores acrescentarão entendimentos não previstos nos trabalhos originais porque estes possuíam objetivos diferentes. Quando eles são confrontados com outros textos, abre-se a possibilidade de um novo tipo de discussão ser iniciada. É por isso que se compreende que desta forma é possível estabelecer correlações necessárias à definição da interatividade no telejornal, refletindo-se sobre as implicações disso, ainda que nem todos os textos tenham sido produzidos com o propósito de abordar esse assunto.

Neste estudo, também serão utilizadas visões de teóricos que procuram definir a interatividade a partir das consequências que isso acarretará à comunicação na tentativa de identificar como as pesquisas sobre o telejornalismo podem aprofundar as questões trazidas por esses autores. Até agora, há a impressão de que o principal ponto destacado pelos textos publicados é que interatividade ocorre com a integração das novas tecnologias à televisão. Mas, seria possível ir além? Caso se responda positivamente, outra pergunta, mais complexa, merece ser lançada: como a interatividade altera o próprio telejornal? Durante este trabalho, haverá a tentativa de apresentar quais os rumos que podem ser percorridos a partir desse questionamento.

\section{INTERATIVIDADE E JORNALISMO}


Os pesquisadores brasileiros observados parecem concordar quanto à existência de diferenças nos tipos de interatividade dos programas televisivos, embora pouco se tente explicar como uma escala de gradações poderia ser montada - algo que autores do campo da internet são mais preocupados em fazer. Alguns autores da comunicação deixam entrever que o ponto máximo da interatividade só seria atingido nos momentos nos quais o receptor se torna uma parte ativa no acompanhamento dos programas. Esta atitude se mostraria visível no uso do controle remoto ${ }^{1}$, pois ele ainda é tido como a principal via de retorno do processo comunicativo na TV, instaurando, para alguns, um percurso bidirecional para as mensagens. Apesar de os pesquisadores se referirem a este fenômeno de modos diferenciados - para alguns, por exemplo, não se poderia falar em bidirecionalidade, pois o caminho de retorno disponível ao telespectador não é o mesmo e nem está em igualdade de condições quando comparado ao canal de comunicação das emissoras -, há a concordância de que a atuação da audiência é uma condição indispensável à interatividade. Nos textos também não é demonstrada explicitamente nenhuma preocupação de o controle remoto ser substituído ou incorporar avanços que modifiquem exponencialmente como ele tem funcionado desde a sua invenção.

De acordo com Médola (2009), a televisão digital, implantada oficialmente no Brasil a partir de dezembro de 2007, traz plenas condições de expandir a interatividade deste veículo a partir da leitura de que o telespectador é um interagente. Nesta característica, está contida a opinião de que o telespectador é uma parte ativa, porém, mais do que isso, este sujeito levaria a experiência de consumo de conteúdo criado com a internet para a TV. Ela aponta que não faria muito sentido se pensar na interatividade na televisão analógica porque neste modelo o público estaria em posição passiva. A interatividade, neste caso, aparece necessariamente integrada a softwares e hardwares, tendo conceitos como usabilidade, metodologia e organização de dados como partes intrínsecas a ela.

Baseada nisso, a autora demonstra uma preocupação quanto à atuação dos profissionais do audiovisual, que neste contexto passam a possuir novas funções e rotinas de trabalho. Em uma perspectiva da semiótica, ela aponta a influência da interatividade também na enunciação, destacando a necessidade de as construções discursivas serem revistas, principalmente quando a convergência entre os meios começa a ser mais utilizada.

\footnotetext{
1 Natário e Wajnman (2006) tratam esse pequeno equipamento como uma interface importante para o funcionamento dos níveis mais avançados de interatividade.
} 
Embora as propostas interativas ainda não estejam em suporte totalmente convergente, a introdução dos efeitos de sentido de uma comunicação interativa cria modalidades diferentes na maneira de fruição de uma televisão que se propõe expandida, forjando novos hábitos de consumo de conteúdos audiovisuais. O exemplo mais recorrente é a convocação para que o telespectador acesse o site da emissora para obter mais detalhes e informações sobre o conteúdo veiculado na TV, no caso dos programas informativos. Mas também as telenovelas, as séries, os reality shows, todos têm uma página na internet na qual o telespectador poderá encontrar de blogs com participação de autores à ficha técnica da equipe de produção (MÉDOLA, 2009, p.4).

Deste trecho, não apenas a interatividade decorrente da atuação do interagente é incluída como também estão sendo considerados os efeitos de sentido proporcionados por uma comunicação interativa. Desta forma, a preocupação vai além das possibilidades tecnológicas, pensando-se sobre como a televisão é consumida pelos telespectadores a partir do momento em que, aliados aos programas, conteúdos extras podem ser acessados em outras plataformas, principalmente pela internet. Ainda que eles não estejam disponíveis por um simples toque no controle remoto, só pelo fato de serem produzidos e poderem ser acessados sob demanda eles estariam alterando a forma de fruição da TV.

No caso do telejornal, a inserção de interatividade teria como principal impedimento o fato de que a sua veiculação ocorre em tempo real. Isso não é levantado como um empecilho nos artigos analisados, contudo, essa característica é colocada por Lima Júnior (2009) como importante na escolha de qual programa assistir. Para ele, dado ao fato de a notícia possuir uma existência curta, a transmissão dela em tempo real justificaria o porquê de as pessoas preferirem este tipo de transmissão frente aos conteúdos gravados. Caso se concorde com isso, parece ser possível inferir que a interatividade poderia ser bem aproveitada pelos programas ao vivo, pois estes conseguiriam incentivar mais facilmente uma atitude ativa de um público que já está amplamente interessado por aquilo a que está assistindo.

Além dessa, outra tendência no jornalismo é dar cada vez mais espaço para o público enviar conteúdos em uma atitude justificada como uma forma diferenciada de relacionamento entre a audiência e as redações. Diante disto, deve-se refletir como esse comportamento pode estar relacionado à interatividade. 
No caso específico do telejornalismo, verificamos, por exemplo, que cada vez mais as grandes emissoras têm utilizado imagens de amadores, em particular de filmes produzidos com telefones celulares - imagens, portanto, que não seguem quaisquer dos critérios profissionais de controle e verificação da informação - como modo justamente de ampliar a autenticidade e a veracidade dos programas telejornalísticos (GOMES, 2007, p.10).

Se realmente existir a preocupação acima de incluir novos produtores para a televisão, uma mudança natural, então, seria planejar os espaços para eles. Há estudos que já se preocupam com esse relacionamento, com a hipótese de os vínculos mais próximos servirem para garantir uma maior fidelização da audiência. A mudança do discurso, por exemplo, dos apresentadores, um mediador central da equipe do telejornal, com os telespectadores é tida como uma característica dessa mudança, assim como a presença desses jornalistas em outras plataformas, particularmente, nas mídias sociais.

No âmbito desse artigo a proposta é avaliar por meio de seu discurso, veiculado em rede nacional de televisão, e ainda com o auxílio de outros suportes, como o programa investe na criação de vínculos com os telespectadores, como em uma espécie de busca por um público para chamar de seu. Nessa perspectiva serão realizadas inferências também a partir da observação de espaços construídos em direção aos telespectadores, quer seja pela emissora ou ainda pelo editor chefe do JN, William Bonner, como a página do JN na rede, a publicação de um livro, ou a alimentação de um perfil-página no twitter (COUTINHO, 2010, p.1).

A partir da citação, pode-se observar que os vídeos classificados acima como amadores só são veiculados porque eles fizerem um percurso inverso aos das mensagens veiculadas massivamente. Para muitos pesquisadores, essa seria uma característica do jornalismo 2.0, em que o consumo passivo das mídias é tomado por uma cultura colaborativa. A partir daí, o jornalismo estaria sendo modificado em sua natureza e em sua prática profissional, como defendem Schimdt, Oliveira e Fialho (2008), acrescentando que essa é uma característica do século XXI.

Poder-se-ia crer que a interatividade na televisão também poderia ser pensada a partir de como os conteúdos desse meio estão sendo estendidos a outros. Embora o twitter de um apresentador de telejornal não seja a mesma coisa que o twitter do programa, o primeiro na maioria das vezes pode, a princípio, reforçar a permanência do público na TV. Nesse raciocínio, o fornecimento de outras vias de acesso ao programa e de seus produtores serviria 
para reforçar o próprio telejornal. A interatividade, mesmo disponível fora da tela da televisão, auxiliaria na manutenção da audiência no telejornal. Como aponta Coutinho (2010), os telejornais estão cada vez mais preocupados em seduzir o público, o que estaria ocorrendo no próprio produto televisivo como também estaria sendo explorado em outras plataformas.

Com um objetivo diferente, em um estudo sobre a qualidade no telejornalismo, Becker (2006) considera que um dos aspectos para se aferir a qualidade na TV é verificar como os produtos audiovisuais conseguem estabelecer novos vínculos entre as pessoas em seu cotidiano.

Conclui-se que a televisão de qualidade é aquela que se torna parte da conversação pública cotidiana, como uma referência de novos conhecimentos e percepções, já que o audiovisual deve servir para conectarse com as pessoas, criando uma relação enriquecedora com a vida cotidiana, expressa por produzir programas inovadores, universais, experimentais e ousados (BECKER, 2006, p.5).

Ainda que não se mencione em nenhum momento no referido texto como a interatividade seria inserida a esse fenômeno, acredita-se que um programa televisivo interativo pode estimular a conversação entre as pessoas, ao facilitar o compartilhamento de interesses em comum. Aliás, esse objetivo deveria ser perseguido na produção de conteúdos interativos no jornalismo, o que necessariamente modificaria os modos como o jornalismo promove o agendamento público. De acordo com Médola (2009), a TV Digital, a partir da interatividade, traz a possibilidade de redemocratização do acesso à informação e um maior incremento na produção audiovisual.

\section{CONSIDERAÇÕES GERAIS SOBRE A INTERATIVIDADE}

A partir das ideias que foram apresentadas no tópico anterior, pretende-se avançar nas reflexões sobre a interatividade no jornalismo, esmiuçando como esse conceito é percebido por pesquisadores que vêm se dedicando aos estudos de tecnologia e comunicação. Com base nesse propósito, iniciamos com Lorenzo Vilches (2003), que anos atrás se questionava sobre o futuro da televisão na defesa da ideia de que esse veículo poderia ser mais inteligente. Por isso, o autor não atrela qualquer modificação na televisão como decorrente de um grande potencial interativo, ele prefere pontuar diferenças nas interatividades. De acordo com ele, quando a TV funde-se a outras mídias, no sentido de serem convergentes, haveria aí a manifestação de uma interatividade fraca. Seguindo o mesmo pensamento, o modelo 
conversacional de apresentar as notícias nos telejornais seria uma falsa interatividade. As renovações estéticas nos cenários também pertenceriam à interatividade simulada.

Desse modo, a interatividade permite aos usuários usarem as mídias para organizar seu espaço e seu tempo, e não o inverso, como aconteceu com os meios tradicionais baseados na manipulação das imagens e dos sons a partir de um centro emissor (VILCHES, 2003, p.23).

No momento em que a obra acima foi escrita, o autor concordava com a existência de uma interatividade real e efetiva, porém ela não poderia ser circunscrita à TV. A interatividade, em sua plenitude, ocorreria a partir de uma nova zona de relações sociais, na qual o homem poderia se aproximar da máquina e fazer uso dela a partir de suas vontades e, claro, em função do serviço disponível. O homem é quem seria o responsável por gerir as suas formas de ver, utilizando as habilidades técnicas em um uso inteligente. É, então, tendo como base esse pressuposto que Vilches (2003) apresenta uma subdivisão para a interatividade, a interatividade técnica e a interatividade comunicativa, demonstrando a sua preferência pela segunda forma, visto que ela conferiria uma função, realmente, diferenciada para os meios de comunicação.

Aliar a interatividade a um significado maior do que aos atos de apertar botões para o liga/desliga da TV, alternar canais, deixar a tela com mais brilho, entre outras alternativas disponíveis para a execução do telespectador em qualquer momento por meio do controle remoto, pertenceria, então, à interatividade técnica. Resta a dúvida, entretanto, de como seria classificada a utilização dos aplicativos interativos. No Brasil, as experiências adotadas até o momento mantêm no controle remoto o poder de ativar a interação com o programa. No telejornal, é conhecida a experiência da Globonews, canal fechado da Rede Globo, permitindo a visualização de conteúdos extras, como manchetes das notícias do dia. Outras iniciativas, como a da TV Integração, afiliada da mesma emissora citada, mas de sinal aberto, estão começando a dispor de aplicativos interativos. Em geral, a base de funcionamento deles é permitir a exploração do próprio canal a que se assiste com informações adicionais ao que está sendo veiculado. Resta a dúvida se essas experiências poderiam deixar de fazer parte da interatividade técnica para se tornarem componentes da interatividade comunicativa. Por enquanto, até pelo fato de os aplicativos ainda estarem sendo testados e só serem disponíveis 
a uma parcela mínima da população ${ }^{2}$, acredita-se que ainda se esteja muito mais perto da primeira.

Uma das maiores referências da atualidade sobre a convergência digital, Jenkins (2008) considera relevante diferenciar a interatividade da participação, apontando que as utilizações delas costumam ser feitas, erroneamente, como se fossem sinônimas. Segundo o norte-americano, a interatividade estaria ligada aos mecanismos pensados e executados pelos produtores de mídia para incluir as respostas dos consumidores. Assim, as diferentes formas de comunicação teriam diversos graus de interatividade, avaliados em função de como o usuário poderia agir a partir do que é determinado pelas possibilidades da interface. Já a participação seria moldada pelos protocolos culturais e sociais, que determinam a aceitação ou não da interatividade nos meios de comunicação. De acordo com essa visão, os modos como a tecnologia é incorporada pelos veículos dependeria principalmente da tolerância do público, pois ele determina quais são as propriedades de cada meio. A participação, ao contrário de como é costumeiramente tratada pelas corporações, não é uma mercadoria a ser encaixotada e vendida. Atualmente, ela é solicitada e controlada pelos próprios consumidores.

Os conceitos de interatividade comunicativa, de Vilches, e de participação, de Jenkins, embora não sejam a mesma coisa, parecem trazer, como consequência, a preocupação semelhante de que a interatividade nas pesquisas de comunicação deve incorporar preocupações diferentes das contidas em outras áreas. Por mais que a interatividade só exista a partir dos programas de computadores e das linguagens que os constituem, a sua presença na televisão precisa ser discutida, levando-se em consideração a integração social deste veículo, como também crê Wolton (2003). Em adição ao que ocorre na coletividade, as formas de comunicação interativas precisam também de estudos sobre a influência desse tipo diferenciado de consumo de mídia na constituição do sujeito em sua individualidade.

Thompson (1998) avalia que o processo comunicativo, embora assimétrico, não é totalmente monológico ou de sentido único, uma vez que a audiência sempre esteve em contato com os centros de produção midiática, por exemplo, com o envio de cartas e com ligações telefônicas. Quando esses dois exemplos ocorrem, os indivíduos se relacionariam com o meio por uma relação de interação mediada, uma categoria diferente da experiência daqueles que não entraram em contato com os centros produtores de mídia. Estes, ao

\footnotetext{
${ }^{2}$ Deve-se alertar, além de uma quantidade pequena de televisores digitais, nem todos os aparelhos saem das fábricas com capacidade de decodificar e ativar os aplicativos interativos. Atualmente, segundo o DTV, 45,98\% da população brasileira recebe a cobertura em UHF.
} 
consumirem produtos com uma linguagem mais coloquial, vivenciariam uma relação de quase-interação mediada. Ainda que Thompson não se detenha nas características tecnológicas dos tipos de interatividade, é visível a sua preocupação em pensar no uso social das formas de interação. O autor destaca ainda como a experiência de constituição do sujeito, o self, está sendo alterada pelas condições do mundo mediado. O sentimento de intimidade com as coisas, por exemplo, não está mais relacionado ao encontro face a face, mas à experiência mediada pela comunicação e informação.

Arlindo Machado (2002) utiliza-se das concepções de Janet Murray, para quem as respostas e ações do usuário em um ambiente interativo produzem o efeito de agenciamento, para apresentar as consequências disso nas mídias que se utilizam da tecnologia para promover novas relações interativas.

Os atuais ambientes tecnológicos de imersão e de agenciamento estão promovendo a ocorrência de um fenômeno novo, que poderíamos definir como sendo a hipérbole do sujeito, uma espécie de narcisismo radical e autor-referenciado, em que a única identificação possível é a do sujeito com ele mesmo. O interator quase sempre se insere nesses ambientes como o seu sujeito e, na maioria dos casos, é impossível vivenciar as narrativas interativas senão encarnando a sua personagem principal, aquela em função da qual os eventos acontecem (MACHADO, 2002, p.6).

A interatividade, que nos estudos mais antigos aparecia vinculada à cibercultura, tendo como ponto inicial as compreensões sobre o hipertexto, coexiste com outros conceitos correlacionados. Se há alguns anos toda a bibliografia concernente ao assunto pertencia aos estudos de internet, hoje é imprescindível a revisão de algumas ideias e a proposição de teorias que não sejam simplesmente adaptações do que foi observado em um determinado tipo de mídia. Em 1998, o pesquisador dinamarquês Jens J. Jensen resumiu a interatividade como uma característica da mídia que permite o usuário influenciar a forma ou o conteúdo da comunicação mediada. A partir dessa visão, ele subdivide a interatividade em quatro tipos: de transmissão, de consulta, de conversação e de registro.

Para chegar a essa proposta, o autor partiu das formas de consumo de informação, tendo como parâmetros como e por quem ela é produzida, controlada e distribuída. Assim, a interatividade de transmissão é aquele em que sobra para o público somente a recepção do conteúdo produzido e distribuído pelas mídias broadcasting e em transmissões unidirecionais em geral, não necessariamente massivos. A interatividade de consulta permite a recepção 
baseada na escolha entre as opções disponíveis, em que a produção é feita por um centro único, porém o consumo e a distribuição são personalizados. Já na interatividade de conversação, o controle, o consumo e a distribuição de informação, ocorrem em via dupla, algo que não acontece na interatividade de registro, onde o controle permanece com um centro provedor, embora seja possível produzir, consumir e distribuir as informações sem imposições.

O mesmo Jensen (2008, p.6) revisou as suas conceituações com o fortalecimento das novas mídias. Sobre a televisão interativa, ele aponta que "mesmo o fenômeno das novas mídias com a conexão interativa da televisão, como o "conteúdo gerado pelo usuário”, "a mídia adaptável/personalizada”, “a mídia customizada”, “o vídeo sob demanda”, etc., pode ser caracterizado com essa tipologia”, uma vez que as quatro formas de consumo dão conta de todas as situações. Segundo o autor, a grande mudança ocorreu entre a mídia standard e as mídias sociais que, se antes agiam separadamente, agora, em uma verdadeira simbiose misturam-se cada vez mais, incluindo alterações no formato, no tempo e no espaço, ainda pouco compreendidas. Portanto, uma das saídas para se pensar como interatividade pode ser inserida aos estudos de telejornalismo consiste em compor um quadro do que seria possível a essa produção com a observação do que já está sendo feito nos dias de hoje e pode ser ainda mais potencializado.

No que se refere aos quatro tipos de interatividades descritas pelo pesquisador dinamarquês, podemos inferir naturalmente a manifestação da interatividade do tipo de transmissão. O funcionamento dos aplicativos do Ginga - middleware desenvolvido no Brasil que permite o desenvolvimento de aplicações interativas para a TV Digital - ainda sem o canal de retorno, demonstra a existência da interatividade do tipo de consulta, em que cabe ao telespectador escolher se deseja ou não ter acesso aos conteúdos extras oferecidos. A interatividade do tipo registro também poderia estar presente em aplicativos, como os que estão sendo testados com celulares, em que dois telespectadores podem estar em contato durante a transmissão de um programa de $\mathrm{TV}^{3}$.

O tipo de interatividade que se mais se assemelha ao que é apresentado como ideal pelos pesquisadores citados por esse texto é o de conversação. A razão disso, talvez, decorra

\footnotetext{
3 A aplicação Torcida Virtual (http://www.hxd.com.br/site/index.php?option=com_content\&task=view\&id =35\&Itemid=80) permite que, durante a transmissão de um jogo de futebol, o telespectador simule a sua presença no estádio. Tudo começa com a escolha do setor e da cadeira, de onde acompanhará a partida. Ele também pode participar de chats e de enquetes.
} 
do entrelaçamento da área da comunicação aos estudos sociais e, portanto, da perspectiva de que a interação - e não a interatividade - é um dos principais fundamentos da vida em sociedade. Evidentemente, pelas características apontadas por Jensen $(1998,2008)$ para se chegar à interatividade de conversação, devem ser estabelecidos diferentes eixos de produção de conteúdo, o que, no caso do jornalismo faz uma referência direta à prática jornalística realizada com a participação de pessoas comuns. Se na internet são notórios os exemplos de informações noticiadas por não-jornalistas, na televisão parecem existirem limites de como a interatividade de conversação pode ser apresentada.

\section{REFLEXÕES SOBRE A INTERATIVIDADE NO TELEJORNALISMO}

Em texto publicado no periódico Television and New Media, a pesquisadora norteamericano Vicki Mayer (2011) opina que os trabalhos sobre a televisão precisam incluir novos temas aos já estudados a fim de que possam intervir no debate atual. A constatação dela é que o termo 'novas mídias’ está sendo usado para coisas existentes há várias décadas, ao mesmo tempo em que muita energia está sendo gasta para pensar o futuro de atividades como linguagem e literatura sem um foco específico que não o argumento de antecipar-se a um novo tempo.

Enquanto isso, a televisão continua em crise. Algumas coisas que nós colocamos sob a chave das 'novas mídias' têm pelo menos trinta anos. É, sem dúvida, irônico que comentadores de televisão e novas mídias frequentemente utilizam termos residuais em seus fóruns, como fluxo, antena, sinais, sem se falar de tela, quadro, box e console. A durabilidade desses termos, apesar das adaptações e transformações, sugere que a resistências das mesmas preocupações motivaram os estudos em TV (MAYER, 2011, p.96).

A referida autora demonstra conhecer não só a pesquisa nos Estados Unidos como descreve informações sobre outros países a exemplo do Brasil. Talvez, ela tenha razão ao detectar um sentimento de angústia dos pesquisadores em adentrar por temáticas diferentes daquelas trabalhadas há vários anos por eles. Isso poderia, ainda de modo insuficiente, explicar porque há uma quantidade pequena de textos na Compós e na E-Compós sobre a 
interatividade no telejornalismo. É claro que tal argumento não invalida outras justificativas sobre as razões pelas quais não se fale diretamente sobre o telejornalismo interativo.

Deve-se pensar ainda que a falta de espaço para a inclusão deste tema não é exclusiva dos estudos acadêmicos, mas também surge nos dizeres dos profissionais atuantes dos meios. Em pesquisa realizada na Espanha, Miranda (2008) realizou entrevistas com jornalistas de diferentes meios (agência de notícias, emissora de televisão, canais de rádio e jornais impresso) e demonstrou que estes profissionais, apesar de considerarem que a interatividade permite uma maior capacidade de a audiência intervir na agenda dos veículos, os exemplos de participação citados continuam necessitando de uma revisão do tipo relacionamento estabelecido com o público. De acordo com este autor, em teoria, os cidadãos e os jornalistas poderiam estabelecer relações com maior intensidade e continuidade. Ainda, segundo ele, o jornalismo sofreu uma rápida modificação de suas formas de produção, cada mais dependente da tecnologia, mas ainda pode atuar de um modo mais rico para a sociedade.

Se é certo que a interatividade pode conferir mais autonomia, também poderá facilitar ou, inclusive tornar imprescindível, que a produção das mensagens seja feita de modo mais permeável às inquietudes da sociedade. Da mesma forma que o jornalista profissional tem que se adaptar individualmente a realidade interativa, os meios de comunicação tradicionais e as equipes profissionais terão que buscar fórmulas de trabalho interativas que permitam diferenciar seu resultado do obtido pelos novos emissores da internet (tradução nossa) (MIRANDA, 2008, p.138).

No telejornal, em que a transmissão de conteúdos produzidos pelos cidadãos continuará dependendo do espaço concedido pelas emissoras, sejam elas públicas ou privadas, a interatividade merece ser pensada não somente em suas possibilidades tecnológicas, porém, principalmente a partir de como a mediação entre público e emissora está sendo empreendida e, naturalmente, quais as consequências disso à própria comunicação. Se, como foi visto, há dificuldades para abordar a interatividade nos telejornais, pois esse produto possui características diferenciadas de meios exclusivamente digitais, acredita-se que as opções de escolha do controle remoto são a última parte do processo, que merece ser melhor compreendido.

\section{CONSIDERAÇÕES FINAIS}


O artigo apontou como os pesquisadores da comunicação, partindo dos autores brasileiros, estão lidando com questões referentes à interatividade e de como esse tema aparece apenas de forma tangencial em duas das principais esferas de discussões da área no Brasil, o evento da Compós e a revista E-Compós, que pertencem à mesma associação de pesquisadores. Ao mesmo tempo, as preocupações demonstradas por autores de renome internacional possuem abordagens que mostram para quais direções estão caminhando as reflexões sobre jornalismo e/ou interatividade sob o viés da comunicação.

As preocupações apontadas pelos pesquisadores nacionais - mesmo tendo sido recolhidas em sua maior parte indiretamente, pois a interatividade no telejornalismo é um assunto ainda pouco presente nos textos dos últimos seis anos - e também pelos autores internacionais podem ser concentradas em três aspectos principais que direcionam para onde as discussões podem ser orientadas. Elas podem ser resumidas em:

1) Deve-se verificar como o telejornal está sendo consumido e quais as alterações já provocadas pela tecnologia, seja pelos equipamentos lançados, seja pelas novas mídias que, agora, estão sendo inseridas a esse formato televisivo;

2) Por consequência, é necessário pensar sobre os espaços e mecanismos permitidos a interferência do público no telejornal, diferenciando-os;

3) E, por fim, é importante refletir sobre como o que vem sendo chamado de interatividade, nas suas mais diferentes fundamentações e manifestações, pode contribuir para uma melhoria do telejornalismo com práticas jornalísticas mais apuradas, auxiliadas por uma cultura de participação capaz de alterar as formas de produção, controle e distribuição da informação.

Dessa forma, apesar de o corpus escolhido representar somente uma pequena parcela da produção acadêmica sobre o assunto, o que foi apresentado trazem preocupações que podem nortear as reflexões sobre a interatividade no telejornalismo. Se foram percebidas lacunas sobre essa questão, as reflexões apontam o público como um agente fundamental de todas as mudanças em andamento. Há também o desejo de que a interatividade no telejornalismo sirva para favorecer uma comunicação mais próxima da comunicação dialógica.

\section{REFERÊNCIAS}

ANIMUS R. Interamericana de Comunicação Midiática, http://www.ufsm.br/revistas E-ISSN 2175-4977, v. 11, n. 21, Jan-Jun(2012) 
BECKER, Beatriz. Telejornalismo de qualidade: um conceito em construção. In: ASSOCIAÇÃO NACIONAL DOS PROGRAMAS DE PÓS-GRADUAÇÃO EM COMUNICAÇÃO, COMPÓS, 15. 2006, Bauru. Anais... Bauru: Unesp, 2006. Disponível em: < http://www.compos.org.br/>. Acesso em: 2 mar.2011.

COUTINHO, Iluska Maria da Silva; CAMBOIM, Ana Flávia de Luna. Um público para chamar de seu: a construção da audiência no Jornal Nacional. In: ASSOCIAÇÃO NACIONAL DOS PROGRAMAS DE PÓS-GRADUAÇÃO EM COMUNICAÇÃO, COMPÓS, 19., 2010, Rio de Janeiro. Anais...Rio de Janeiro: PUC, 2010. Disponível em: < http://www.compos.org.br/>. Acesso em: 2 mar.2011.

GOMES, Itania Maria Mota. Questões de método na análise do telejornalismo: premissas, conceitos, operadores de análise. E-Compós, v.8, 2007. Disponível em: < http://www.compos.org.br/seer/index.php/e-compos/issue/view/8>. Acesso em: 10 mar. 2011.

JENKINS, Henry. Cultura da Convergência. São Paulo: Aleph, 2008.

JENSEN, Jens F. The concept of interactivity - revisited: four new typologies for a new media landscape. UXTV, FIRST INTERNATIONAL CONFERENCE ON DESIGNING INTERACTIVE USER EXPERIENCE FOR TV AND VIDEO, 1., 2008. Califórnia. Anais... Silicon Valley, 2008. Disponível em: <http://portal.acm.org/citation.cfm?id=1453831>. Acesso em: 10 abr 2011.

Interactivity. Tracking a new concept in media and communication studies. Nordicom Review, vol. 19, 1998. Disponível em: < http://www.organicode.net/jenson.pdf $>$. Acesso em: 10 abr.2011.

LIMA JUNIOR, Walter Teixeira. Vetores estruturantes na construção da percepção no noticiário em “tempo real”. E-Compós, v.12, n.2, 2009. Disponível em: < http://www.compos.org.br/seer/index.php/e-compos/issue/view/19> . Acesso em: 10 mar.2011.

MACHADO, Arlindo. Regimes de imersão e modos de agenciamento. In: SOCIEDADE BRASILEIRA EM ESTUDOS INTERDISCIPLINARES DA DA COMUNICAÇÃO, INTERCOM, 25., 2002, Salvador. Anais... Salvador: Uneb, 2002. Disponível: <http://galaxy.intercom.org.br8180/dspace/bitstream/1904/ 18810/1/2002_>. Acesso em: 4 mar. De 2011

MANOVICH, Lev. The languaje of new media. Cambridge: MIT Press, 2001.

MAYER, Vicki. New television and media?. Revista Television and new media. Disponível em: http://tvn.sagepub.com/. Acesso em: 10 mar. 2011.

MÉDOLA, Ana Silvia Lopes Davi. Televisão digital brasileira e os novos processos de produção de conteúdos: os desafios para o comunicador. E-Compós v.12, n.3, 2009. Disponível em: < http://www.compos.org.br/seer/index.php/e-compos/issue/view/20>. Acesso: 4 mar.2011.

MIRANDA, José María García de Madariaga. El periodismo em el siglo XXI: una profesión ante la digitalización. Madrid: Dykinson, 2008.

SCOLARI, Carlos. Hacia la hipertelevisón: los primeiros sintomas de uma nueva configuración del dispositivo televisivo. Diálogo de la communicación, n.77, 2008. Disponível em: <http://www.dialogosfelafacs.net/77/articulo_resultado.php?>. Acesso em: 4 mar. de 2011.

ANIMUS R. Interamericana de Comunicação Midiática, http://www.ufsm.br/revistas E-ISSN 2175-4977, v. 11, n. 21, Jan-Jun(2012) 
SCHMITT, Valdenise; OLIVEIRA, Leonardo Gomes de; FIALHO, Francisco Antonio Pereira. Jornalismo 2.0: a cultura da colaboração no jornalismo. E-Compós, v.11, n.3, 2008. Disponível em: < http://www.compos.org.br/seer/index.php/e-compos/issue/view/15>. Acesso em: 5 mar. 2011.

THOMPSON, John B. A mídia e a modernidade: uma teoria social da mídia. 7 ed. Petrópolis: Vozes, 1998.

VILCHES, Lorenzo. A migração digital. São Paulo: Loyola, 2003.

WOLTON, Dominique. Internet, e depois? Uma teoria crítica das novas mídias. Porto Alegre: Sulina, 2003.

Original recebido em: 28/04/2011

Aceito para publicação em: 10/07/2012

Resumo sobre o autor

Talita Rampazzo Diniz é doutoranda do PPGCOM/UFPE, mestre em Comunicação e jornalista. 